\title{
Mass Spectrum of Sulfur Vapor
}

\author{
Paul Bradt, Fred L. Mohler, and Vernon H. Dibeler
}

\begin{abstract}
The mass spectrum of sulfur vapor has been measured by evaporating sulfur from a heated tube directly into the ionization chamber of a mass spectrometer. Ions $\mathrm{S}_{x}^{+}$with $x$ ranging from 1 to 8 are observed with $\mathrm{S}_{2}^{+}$most abundant. Isotope abundances were computed from the $\mathrm{S}_{2}^{+}$ions. The appearance potentials of $\mathrm{S}_{8}^{+}$and $\mathrm{S}_{2}^{+}$are respectively $8.9 \pm 0.2$ and $8.3 \pm 0.2$ electron volts. This suggests that the vapor in the ionization chamber is a mixture of molecules containing $S_{2}$ and $S_{8}$ and possibly other molecules.
\end{abstract}

\section{Introduction}

The mass spectrum of sulfur vapor has been studied in connection with a program to establish reference samples of natural isotopic abundance [1]. ${ }^{1}$ While one objective of this study was to check the isotope ratios and the chemical purity of the reference sample, the mass spectrum and the appearance potentials are of research interest. The molecular weight of sulfur vapor indicates that the vapor in equilibrium with sulfur at $175^{\circ} \mathrm{C}$ is predominantly $\mathrm{S}_{8}[2]$. This is a relatively unstable configuration, and in the presence of an electric discharge an $\mathrm{S}_{2}$ band spectrum is observed [3]. The vibration series and predissociation spectra give with some uncertainty a value of $4.4 \mathrm{ev}$ for the $\mathrm{S}_{2}$ bond energy, indicating that $\mathrm{S}_{2}$ is quite stable.

\section{Experimental Procedure}

The sulfur from the reference-sample stock is virgin sulfur from a dome in Wharton County, Tex. The sulfur-vapor pressure is too small to measure the mass spectrum at room temperature, and the measurements were made by evaporating the sulfur from a heated tube into the ionization chamber of a $60^{\circ}$ mass spectrometer. A few milligrams of coarse powder were held in a capillary tube with a thermocouple in contact with the tube. This in turn was in a $6-\mathrm{mm}$ tube, which extended about $2 \mathrm{~cm}$ to the entrance port of the ionization chamber. The ionization chamber reached a temperature of $186^{\circ} \mathrm{C}$ during operation, and the sample attained a steady temperature of $94^{\circ} \mathrm{C}$ by heat conduction and radiation. This proved to be a convenient temperature for recording the spectrum.

Sulfur dioxide was made by burning the sulfur in air, and the mass spectrum of $\mathrm{SO}_{2}$ and the air oxygen was measured with a $180^{\circ}$ gas-analysis mass spectrometer. This is the conventional method of measuring sulfur-isotope abundances.

\footnotetext{
1 Figures in brackets indicate the literature references at the end of this paper.
}

\section{Results}

\subsection{Mass Spectrum}

Table 1 gives the principal ions observed in the mass spectrum of sulfur vapor. Column 3 gives the relative abundance of the ions $\mathrm{S}_{x}^{32}$, whereas column 4 gives the monoisotopic spectrum. It is the sum of the isotope peaks in each $\mathrm{S}_{x}$ group relative to the $\mathrm{S}_{2}$ ions taken as 100 . The rather complicated isotope structure identifies all these ions as predominantly singly charged ions, except for the following: Mass 16 from $\mathrm{S}^{++}$was 0.05 percent of the 64 peak in a spectrum where $\mathrm{O}^{+}$from $\mathrm{O}_{2}$ and $\mathrm{CO}_{2}$ was negligible. Mass $32 \frac{1}{2}$ from $\mathrm{S}^{32} \mathrm{~S}^{33++}$ was 0.06 percent of the 64 peak, and is about 4 percent of the 65 peak. Hence, doubly charged ions of mass 64 contribute 4 percent to the 32 peak. A peak at mass 80 from $\mathrm{S}_{5}^{++}$is 0.06 percent of the 64 peak.

Impurities that can be ascribed to the sulfur rather than the mass-spectrometer background are volatile gases, which decrease with time. $\mathrm{H}_{2} \mathrm{~S}^{+}$ranged from 1.2 to 0.15 percent of the 64 peak, and $\mathrm{CS}_{2}^{+}$was 0.13 to 0.07 percent. A 48 peak ranging from 0.17 to 0.02 percent may be $\mathrm{SO}^{+}$from $\mathrm{SO}_{2}$. The molecule ion masked by $\mathrm{S}_{2}^{+}$would be about twice the $\mathrm{SO}^{+}$ peak.

TABLE 1. Mass spectrum of sulfur vapor

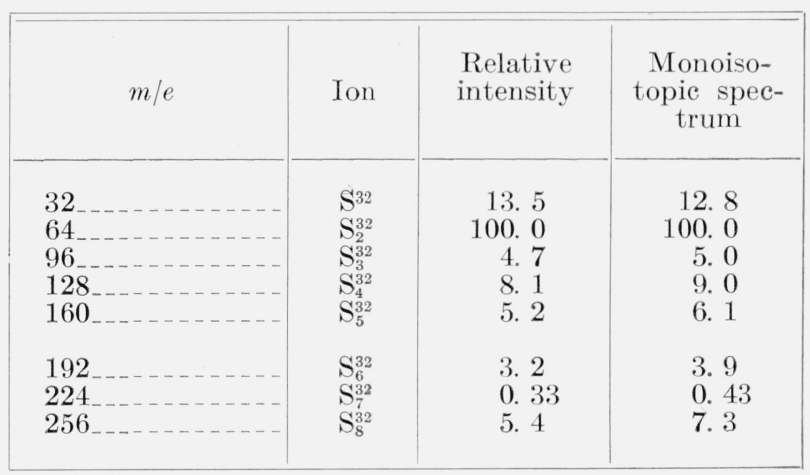




\subsection{Isotope Ratios}

Sulfur has four isotopes of abundance $\mathrm{S}^{32}$, 95.0; $\mathrm{S}^{33}, 0.76 ; \mathrm{S}^{34}, 4.2 ; \mathrm{S}^{36}, 0.014$ (see table 2). The relative intensity of the isotope peaks in a molecule containing $x$ atoms can be expressed formally by means of the $x$ power of the expression,

$$
\mathrm{S}^{32}+a_{1} \mathrm{~S}^{33}+a_{2} \mathrm{~S}^{34}+a_{3} \mathrm{~S}^{36},
$$

where the $a$ 's are abundances relative to that of $\mathrm{S}^{32}$ as unity, but the $\mathrm{S}$ terms are chemical symbols, not algebraic terms. Thus the isotopes of $\mathrm{S}_{2}$ give the terms :

$$
\begin{gathered}
\mathrm{S}^{32} \mathrm{~S}^{32}+2 a_{1} \mathrm{~S}^{32} \mathrm{~S}^{33}+2 a_{2} \mathrm{~S}^{32} \mathrm{~S}^{34}+a_{1}^{2} \mathrm{~S}^{33} \mathrm{~S}^{33}+2 a_{1} a_{2} \mathrm{~S}^{33} \mathrm{~S}^{35}+ \\
2 a_{3} \mathrm{~S}^{32} \mathrm{~S}^{36}+a_{2}^{2} \mathrm{~S}^{34} \mathrm{~S}^{34}+2 a_{1} a_{3} \mathrm{~S}^{33} \mathrm{~S}^{36}+2 a_{2} a_{3} \mathrm{~S}^{34} \mathrm{~S}^{36}+a_{3}^{2} \mathrm{~S}^{36} \mathrm{~S}^{36} .
\end{gathered}
$$

Collecting terms of equal-mass numbers gives the relative intensities of the $\mathrm{S}_{2}$ ions as listed in column 2 of table 2. Because of intensity and resolution, the $\mathrm{S}_{2}$ ions are best adapted to deriving isotope ratios, and mass peaks $64,65,66$, and 68 were used to determine $a_{1}, a_{2}$, and $a_{3}$. Five successive slow scans of the $S_{2}$ peaks under steady conditions gave the relative intensities listed in column 3, where uncertainties listed are the maximum spread of the data. In these measurements the 64 peak was about 5,600 scale divisions on the most sensitive scale, and a small drift in the 64-peak height was corrected by a linear interpolation to the positions of the measured peaks on the record. The fourth column gives

\begin{tabular}{|c|c|c|c|}
\hline $\mathrm{m} / \mathrm{e}$ & $\begin{array}{c}\text { Relative } \\
\text { intensities }\end{array}$ & $\begin{array}{c}\text { Observed } \\
\text { intensities }\end{array}$ & $\begin{array}{c}\text { Derived ralative } \\
\text { abundances }\end{array}$ \\
\hline $\begin{array}{l}64 \ldots \\
65_{\ldots} \\
66 \ldots \\
67_{\ldots \ldots} \\
68_{\ldots-} \\
69 \ldots \\
70_{\ldots-} \\
72_{\ldots-}\end{array}$ & $\begin{array}{l}1 \\
2 a_{1} \\
2 a_{2}+a_{1}^{2} \\
2 a_{1} a_{2} \\
2 a_{3}+a_{2}^{2} \\
\\
2 a_{1} a_{3} \\
2 a_{2} a_{3} \\
a_{3}^{2}\end{array}$ & $\begin{array}{l}1 \\
0.01596 \pm 7 \\
.08897 \pm 20 \\
.00228 \pm 2 \\
\end{array}$ & $\begin{array}{l}a_{1}=0.00798 \pm 4 \\
a_{2}=0.04445 \pm 20 \\
a_{3}=0.00015 \\
\end{array}$ \\
\hline
\end{tabular}
the derived relative abundances.

TABLE 2. Isotope abundances and relative intensities of $\mathrm{S}_{2}$ ions

Table 3 gives percentage abundances from data of table 2 and values derived from the mass spectrum of $\mathrm{SO}_{2}$ made from this sulfur. The correction for $\mathrm{O}_{2}$ isotopes was based on measurements of the air oxygen used in making $\mathrm{SO}_{2}$. The table also includes published values from $\mathrm{SO}_{2}$ spectra.

The $S_{2}$ ions are not favorable for the computation of $a_{3}$, for the contribution of $2 a_{3}$ to the 68 peak is only 15 percent of the $a_{2}^{2}$ term. A source of uncertainty in evaluating $a_{1}$ from the 65 peak arises from the possibility that a trace of $\mathrm{S}_{3}^{32} \mathrm{~S}^{34++}$ may be present. The comparative values of table 2 give no

\begin{tabular}{|c|c|c|c|c|}
\hline & \multicolumn{4}{|c|}{ Mass number } \\
\hline & 32 & 33 & 34 & 36 \\
\hline $\mathrm{S}_{2}^{+}$(sulfur vapor) $\ldots . . .$. & 95.0 & $0.76 \pm 0.004$ & 4. $22 \pm 0.01$ & 0.014 \\
\hline $\begin{array}{l}\mathrm{SO}_{2} \text { (same sulfur) } \\
\text { Nier [5] } \\
\text { Thode [6] sulfur from } \\
\text { same region }\end{array}$ & $\begin{array}{l}95.0 \\
95.1 \\
--.\end{array}$ & $\begin{array}{l}.77_{2} \pm .01 \\
.74 \pm .02 \\
\end{array}$ & $\begin{array}{l}\text { 4. } 23 \pm .07 \\
\text { 4. } 20 \pm .1 \\
\text { 4. } 293\end{array}$ & $.016 \pm .0016$ \\
\hline
\end{tabular}
evidence of this.
TABLE 3. Sulfur-isotope abundances

\subsection{Appearance Potentials}

Some measurements of appearance potentials were made to see whether or not $\mathrm{S}_{2}^{+}$was a fragment ion from $\mathrm{S}_{8}$ ionization. The experimental conditions were not well adapted to accurate measurements. The ion-repeller voltage was kept rather high to maintain sensitivity, and there were irregularities in the current-voltage curves that may come from surface charges on adsorbed sulfur. Mercury vapor was introduced with the sulfur vapor, and the appearance potentials of sulfur ions were measured relative to that of $\mathrm{Hg}^{+}$(spectroscopic value 10.34 ev) [4]. Measurements are based on semilog plots, with current plotted on a scale to make the ion current at $50 \mathrm{v}$ unity. Values of the appearance potentials at an ordinate of 0.003 of the current at $50 \mathrm{v}$ are: $\mathrm{S}_{8}^{+} 8.9 \pm 0.2 \mathrm{ev}$ and $\mathrm{S}_{2}^{+} 8.3 \pm 0.2 \mathrm{ev}$. Variations in the slopes of the current-voltage curves give some added uncertainty. Some measurements on $\mathrm{S}^{+}$indicate an appearance potential roughly $2 \mathrm{v}$ higher than $\mathrm{S}_{2}^{+}$and $\mathrm{S}_{8}^{+}$. A search for negative ions gave negative results, but there was no basis to appraise the sensitivity for negative-ion detection.

\section{Discussion}

The fact that the appearance potential of $\mathrm{S}_{2}^{+}$is somewhat less than that of $\mathrm{S}_{8}^{+}$suggests that $\mathrm{S}_{2}$ molecules are present and $8.3 \mathrm{ev}$ is the ionization potential of $\mathrm{S}_{2}$. Ionization resulting in a pair of positive and negative ions could give fragment ions at an appearance potential less than the ionization potential of the $\mathrm{S}_{8}$ molecule, but there is no evidence that this occurs. As vapor in the ionization chamber is at a pressure less than $10^{-4} \mathrm{~mm}$ and at a temperature of $186^{\circ} \mathrm{C}$, dissociation of $\mathrm{S}_{8}$ into the relatively stable $\mathrm{S}_{2}$ molecule is not unexpected. The mass spectrum of sulfur vapor given in table 1 is probably to be interpreted as the spectrum of a mixture of molecules.

The appearance potentials are unexpectedly low. Smyth and Blewett [7] reported an appearance potential of $10.7 \pm 0.3$ ev for $\mathrm{S}_{2}^{+}$from thermally dissociated $\mathrm{CS}_{2}$, as compared with $8.3 \mathrm{ev}$ found in this work. An ionization potential of $\mathrm{S}_{2}$ lower than that observed by Smyth and Blewett is suggested by analogy with $\mathrm{O}_{2}$. The ionization potential of $\mathrm{O}$ is $13.61 \mathrm{ev}$ [4] and that of $\mathrm{O}_{2}$ is $12.2 \mathrm{ev}$ [8]. As the ionization potential of $\mathrm{S}$ is $10.36 \mathrm{ev}$ [4], the ionization potential of $\mathrm{S}_{2}$ is expected to be considerably lower than this, not slightly higher as reported by Smyth and Blewett. 
The isotope ratios of sulfur are fairly consistent with published values, as is evident in table 2 , but there is considerable variation in isotope abundances of sulfur. Thode and his colleagues [6] have made an intensive survey of relative abundances of $\mathrm{S}^{34}$ in sulfur from various sources and find values ranging from 4.39 to 4.19 percent, with a value of about 4.29 percent reported for native sulfur from the same region as the reference sample.

Washington, May 9, 1956.

\section{References}

[1] F. L. Mohler, Science 122, 334 (1955).

[2] G. B. Guthrie, Jr., D. W. Scott, and G. Waddington, J. Am. Chem. Soc. 76,1488 (1954).

[3] A. G. Gaydon, Dissociation energies and spectra of diatomic molecules (John Wiley \& Sons, Inc., New York, N. Y., 1947).

[4] Charlotte E. Moore, Atomic energy levels I, NBS Circ. 467 (1949).

[5] A. O. C. Nier, Phys. Rev. 53, 282 (1938).

[6] H. G. Thode, R. K. Wanless, and R. Wallouch, Geochim. et Cosmochim. Acta 5, 286 (1954).

[7] H. D. Smyth and J. P. Blewett, Phys. Rev. 46, 276 (1934).

[8] T. M. Sugden and W. C. Price, Trans. Faraday Soc. 44, 116 (1948). 